\title{
Gangrenous gas necrosis of the spleen: a case report
}

\author{
Jeremy Meyer ${ }^{1 *}$ D, Arnaud Dupuis ${ }^{1}$, Benedikt D. Huttner², Matthieu Tihy ${ }^{3}$ and Léo Bühler ${ }^{1}$
}

\begin{abstract}
Background: Splenic abscess usually arises from hematogenous spread. Causative pathogens are various and anaerobic pathogens are rarely reported.

Case presentation: We report the case of a 50-year-old male patient who was admitted for sepsis due to gangrenous necrosis of the spleen associated with bacteremia. Causative pathogens were Clostridium perfringens and Streptococcus gallolyticus. The patient was successfully treated by splenectomy and targeted intravenous antibiotics. No underlying or predisposing disease was found.

Conclusion: Gangrenous necrosis of the spleen is a rare entity that can be successfully treated by splenectomy and antibiotics.
\end{abstract}

Keywords: Splenic abscess, Splenic gangrene, Spleen, Gangrene, Spontaneous gas gangrene

\section{Background}

Splenic abscess constitutes an uncommon entity, usually arising from hematogenous spread [1, 2]. Numerous different causative pathogens have been reported in the literature such as Escherichia coli, Proteus mirabilis, Streptococcus spp., Klebsellia pneumoniae, Staphylococcus aureus, Salmonella spp., Enterococcus spp., Pseudomonas spp. [2-6]. Predominant anaerobic pathogens were reported to be Peptostreptococcus spp., Bacteroides spp., Fusobacterium spp., Clostridium spp. and Propionibacterium acnes $[4,7]$. Splenic abscess of fungal origin may arise in immunocompromised patients, such as those with HIV or hematological cancer [3]. Diagnosis is usually made by ultrasonography or computed tomography. Treatment relies either on percutaneous drainage $[8,9]$ or surgery. However, due to the high failure rate of percuteanous drainage, surgery (splenectomy) often constitutes the definitive treatment for splenic abscesses.

Here, we report the rare case of a spontaneous splenic abscess due to Clostridium perfringens and Streptococcus gallolyticus in an immunocompetent patient.

\footnotetext{
* Correspondence: jeremy.meyer@hcuge.ch

'Division of Digestive Surgery, University Hospitals of Geneva, Rue

Gabrielle-Perret-Gentil 4, 1211 Genève 14, Switzerland

Full list of author information is available at the end of the article
}

\section{Case presentation}

We report the case of a 50 year old male patient, known for a ischemic cerebral ischemia due to a foramen ovale in 1997, closure of that foramen in 2010, who was complaining of left flank abdominal pain and fever since 4 days. He went to a private clinic twice and was discharged with symptomatic treatment and without antibiotics. The patient had no history of trauma. At physical examination, we noted the presence of a fever at $38.6{ }^{\circ} \mathrm{C}$, tachycardia at $100 \mathrm{bpm}$ but normal blood pressure. The left flank was sensitive at palpation without rebound pain. Blood tests indicated acute inflammation, with a leukocytosis at $17.2 \mathrm{G} / \mathrm{l}$ and a CRP value at $337 \mathrm{mg} / \mathrm{l}$. Hemoglobin, hemostasis parameters, creatinine, liver and pancreatic tests were within the normal ranges. Arterial blood $\mathrm{pH}$ and lactate values were also normal. Computed tomography showed a necrosis of the spleen with air, associated with a thin ipsilateral pleural effusion (Fig. 1a). The patient received 31 of cristalloids, ceftriaxone and metrodinazole and was transferred to intensive care unit for monitoring. Blood cultures were positive for Clostridium perfringens and Streptococcus gallolyticus. Antibiotics were switched to amoxicillineclavulamate and clindamycin, the latter for its potential effect on clostridial toxin production through interference with ribosomal protein synthesis [10]. A transthoracic cardiac utrasonography was performed and showed a normal 

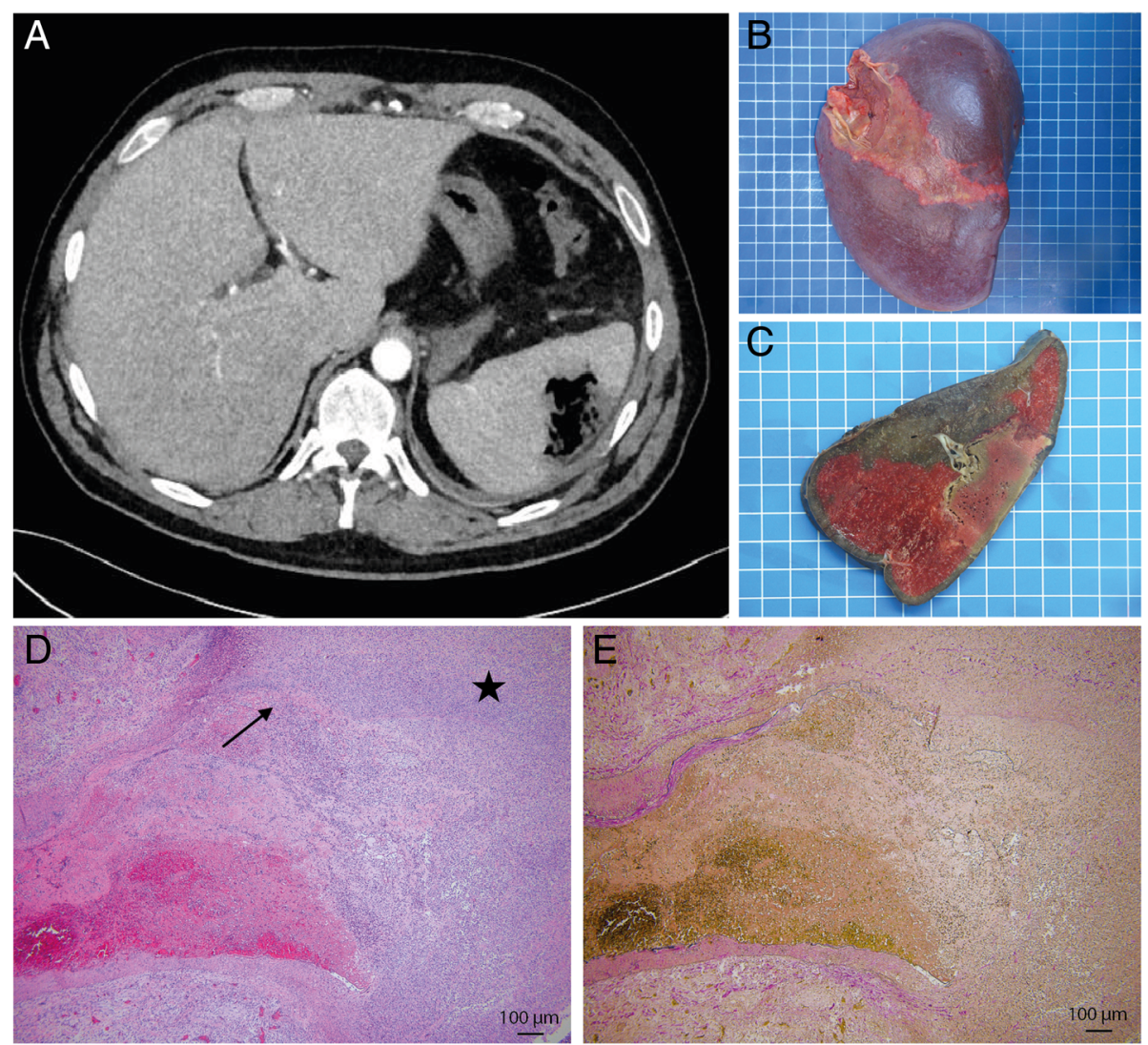

Fig. 1 a Computed tomography axial picture showing the necrotic splenic abscess, b Operative specimen (spleen), c Sagittal section of the operative specimen (spleen), d-e Photomicrographs of the aneurysm of the splenic artery (D. H\&E staining and E. Miller's Elastin Staining) showing destruction of the tunica media (arrow) surrounded by splenic infarction (star)

cardiac function without valvular dysfunction nor endocarditis. After $12 \mathrm{~h}$, we performed a splenectomy by midline incision. Samples of perisplenic purulent liquid were harvested. The spleen was exposed, allowing visualizing a voluminous perforated abscess (Fig. 1b-c). Short vessels were sectioned using a sealing device and main vessels were controlled using non-absorbable ligatures, staying at distance from the pancreas. The spleen was extracted. After local washing, a drain was left in place, the abdominal wall was closed using absorbable stiches and a prophylactic cutaneous negative therapy device was applied. Perioperative bacteriological samples were positive for Clostridium perfringens, Streptococcus gallolyticus and Clostridium baratii. The patient stayed $24 \mathrm{~h}$ in perioperative care unit before returning to the ward. The drain was removed after 6 days and antibiotics were continued for 14 days. Endocarditis was definitively excluded using transoesophageal ultrasonography. HIV serology was negative. To rule out associated pathology of the gastrointestinal tract, a colonoscopy was performed and was normal. The patient was vaccinated against Streptococcus pneumonia, Neisseria meningitidis and Influenza, before being discharged 17 days after admission. Microscopic pathologic examination showed also a ruptured aneurysm (Fig. 1d-e) of a branch of the splenic artery, surrounded by a splenic infarction.

\section{Discussion}

We report the case of a splenic abscess of polymicrobial origin, due to Clostridium spp and Streptococcus gallolyticus with gas gangrene. The patient was successfully managed by splenectomy and 2 weeks of targeted antibiotic treatment. Clostridium perfringens and Streptococcus gallolyticus were identified from blood cultures, whereas another pathogen, Clostridium baratii was retrieved from the perisplenic liquid. Anaerobic splenic abscesses due to Clostridium perfringens are seldom reported in the literature $[4,7,11,12]$. In most cases, a predisposing factor exists, as immunodeficiency, hematologic disease, trauma or infectious [12, 13]. Further, spontaneous gas gangrene is mostly due to Clostridium septicum and cases due to Clostridium perfringens are rarely reported [13-15]. Splenic aneurysm is also a rare complication of infectious diseases, trauma or disorders of the haematopoietic system but could also occur spontaneously [16-19]. 
In our case, the patient was immunocompetent, did not have hematologic disease, evidence for endocarditis nor history of trauma whose origin we assume was probably hematogenic.

Bacteriemia due to Clostridium spp. and especially Streptococcus gallolyticus is reported to be associated with gastrointestinal diseases, especially colorectal cancer [16]. Therefore, we performed a colonoscopy, which did not show any signs of colonic neoplasia. Also, bacterial translocation following for example an episode of gastroenteritis is unlikely, as the patient had no diarrhea or vomiting.

In conclusion, we report the case of a splenic abscess of polymicrobial origin, due to Clostridium spp. and Streptococcus gallolyticus with gas gangrene, in an immunocompetent patient without any evidence for endocarditis or trauma. The patient was successfully treated by splenectomy and antibiotics and could be discharged 17 days after admission. Attention should be given to exclude endocarditis, immunosuppression and colonic diseases in such patients.

\section{Acknowledgements}

None.

\section{Authors' contributions}

$J M$ designed the manuscript. JM, AD, BDH, MT and $L B$ wrote the manuscript and contributed to its critical revision. JM, AD, BDH, MT and LB accepted the final version of the manuscript. All authors read and approved the final manuscript.

\section{Funding}

No funding was received.

\section{Availability of data and materials} n/a.

\section{Ethics approval and consent to participate}

Ethics approval was not required from the local ethics committee. The patient has given his consent to participate.

\section{Consent for publication}

Written informed consent was obtained from the patient for publication of this Case Report and any accompanying images. A copy of the written consent is available for review by the Editor of this journal.

\section{Competing interests}

The authors declare that they have no competing interests.

\section{Author details}

${ }^{1}$ Division of Digestive Surgery, University Hospitals of Geneva, Rue Gabrielle-Perret-Gentil 4, 1211 Genève 14, Switzerland. ${ }^{2}$ Division of Infectious Diseases, University Hospitals of Geneva, Rue Gabrielle-Perret-Gentil 4, 1211 Genève 14, Switzerland. ${ }^{3}$ Division of Pathology, University Hospitals of Geneva, Rue Gabrielle-Perret-Gentil 4, 1211 Genève 14, Switzerland.

Received: 6 May 2019 Accepted: 25 August 2019

Published online: 05 September 2019

\section{References}

1. Robinson SL, Saxe JM, Lucas CE, et al. Splenic abscess associated with endocarditis. Surgery. 1992;112:781-6; discussion 786-7.

2. Lee $\mathrm{CH}$, Leu HS, Hu TH, et al. Splenic abscess in southern Taiwan. J Microbiol Immunol Infect. 2004;37:39-44.
3. Ferraioli G, Brunetti E, Gulizia R, et al. Management of splenic abscess: report on 16 cases from a single center. Int J Infect Dis. 2009;13:524-30.

4. Brook I, Frazier EH. Microbiology of liver and spleen abscesses. J Med Microbiol. 1998:47:1075-80.

5. Chang KC, Chuah SK, Changchien CS, et al. Clinical characteristics and prognostic factors of splenic abscess: a review of 67 cases in a single medical center of Taiwan. World J Gastroenterol. 2006;12:460-4.

6. Lee WS, Choi ST, Kim KK. Splenic abscess: a single institution study and review of the literature. Yonsei Med J. 2011;52:288-92.

7. Gangahar DM, Delany HM. Intrasplenic abscess: two case reports and review of the literature. Am Surg. 1981;47:488-91.

8. Zerem E, Bergsland J. Ultrasound guided percutaneous treatment for splenic abscesses: the significance in treatment of critically ill patients. World J Gastroenterol. 2006;12:7341-5.

9. Thanos L, Dailiana T, Papaioannou G, et al. Percutaneous CT-guided drainage of splenic abscess. AJR Am J Roentgenol. 2002;179:629-32.

10. Stevens DL, Maier KA, Mitten JE. Effect of antibiotics on toxin production and viability of Clostridium perfringens. Antimicrob Agents Chemother. 1987:31:213-8.

11. White MT, Diebel LN, Dulchavsky SA. Clostridial splenic abscess: diagnosis, treatment, and outcome. Am J Gastroenterol. 1995;90:1891-2.

12. Kitterer $\mathrm{D}$, Braun $\mathrm{N}$, Jehs $\mathrm{MC}$, et al. Gas gangrene caused by clostridium perfringens involving the liver, spleen, and heart in a man 20 years after an orthotopic liver transplant: a case report. Exp Clin Transplant. 2014;12:165-8.

13. Lee $H L$, Cho SY, Lee DG, et al. A fatal spontaneous gas gangrene due to Clostridium perfringens during neutropenia of allogeneic stem cell transplantation: case report and literature review. Infect Chemother. 2014;46:199-203.

14. Yildiz T, Gundes S, Willke A, et al. Spontaneous, nontraumatic gas gangrene due to Clostridium perfringens. Int J Infect Dis. 2006;10:83-5.

15. Dumas G, Tankovic J, Bige N, et al. Clostridium perfringens related spleen gangrene. Intensive Care Med. 2017;43:1730-1.

16. Charokopos NA, Foroulis CN, Rouska EG, et al. Fatal rupture of splenic artery mycotic aneurysm after mitral valve replacement for infective endocarditis. Eur J Cardiothorac Surg 2009;36:783-4; author reply 784-5.

17. Gorg C, Colle J, Gorg K, et al. Spontaneous rupture of the spleen: ultrasound patterns, diagnosis and follow-up. Br J Radiol 2003;76:704-11.

18. Windham TC, Risin SA, Tamm EP. Spontaneous rupture of a nontraumatic intrasplenic aneurysm. N Engl J Med 2000;342:1999-2000.

19. Benjamin B, Kan M, Schwartz D, et al. The possible significance of Clostridium spp. in blood cultures. Clin Microbiol Infect 2006;12:1006-12.

\section{Publisher's Note}

Springer Nature remains neutral with regard to jurisdictional claims in published maps and institutional affiliations.
Ready to submit your research? Choose BMC and benefit from:
- fast, convenient online submission
- thorough peer review by experienced researchers in your field
- rapid publication on acceptance
- support for research data, including large and complex data types
- gold Open Access which fosters wider collaboration and increased citations
- maximum visibility for your research: over $100 \mathrm{M}$ website views per year
At $\mathrm{BMC}$, research is always in progress.
Learn more biomedcentral.com/submissions 